\title{
Intraoperative and postoperative effects of TEG-guided platelet transfusion on antiplatelet drug-related intracerebral hemorrhage patients
}

\author{
HAO ZHOU, LI CHEN and HONGTIAN HE
}

Department of Blood Transfusion, The First Affiliated Hospital of Bengbu Medical College, Bengbu, Anhui 233000, P.R. China

Received June 20, 2018; Accepted December 28, 2018

DOI: $10.3892 / \mathrm{etm} .2019 .7169$

\begin{abstract}
Intraoperative and postoperative effects of platelet transfusion on antiplatelet drug-related intracerebral hemorrhage $(\mathrm{ICH})$ patients were investigated. A retrospective study on $82 \mathrm{ICH}$ patients undergoing emergency surgical treatment caused by antiplatelet drugs was conducted. Among them, 51 patients treated with platelet transfusion served as the observation group and 31 patients without platelet transfusion as the control group. The intraoperative and postoperative bleeding volume, blood transfusion volume and the rate of secondary bleeding were compared between observation and control group under the guidance of thromboelastography (TEG). The coagulation routine examination results of the two groups before surgery were in the normal range, but TEG indicated an excessive inhibition of platelet function (platelet inhibition rate $>89 \%$ ). The platelet number after treatment increased significantly in the two groups of patients and it was significantly higher in observation group than that in control group $(\mathrm{P}<0.05)$. The intraoperative bleeding volume in observation group was significantly lower than that in control group. The total blood transfusion volume in observation group was significantly lower than that in control group $(\mathrm{Z}=2.681, \mathrm{P}=0.036)$, the postoperative hematoma residual volume in observation group was significantly lower than that in control group $(\mathrm{t}=2.145$, $\mathrm{P}=0.035$ ), and the drainage volume in observation group was significantly lower than that in control group $(\mathrm{t}=2.401, \mathrm{P}=0.019)$. Only $3.92 \%$ of the patients in observation group and $19.35 \%$ in control group had secondary surgery, and the difference of the recurrence rate of secondary bleeding between the two groups was statistically significant $\left(\chi^{2}=3.610, \mathrm{P}=0.048\right)$. TEG detection indicator can more comprehensively and accurately evaluate
\end{abstract}

Correspondence to: Professor Hao Zhou, Department of Blood Transfusion, The First Affiliated Hospital of Bengbu Medical College, 287 Changhuai Road, Bengbu, Anhui 233000, P.R. China E-mail: hqp2wq@163.com

Key words: platelet transfusion therapy, antiplatelet drug-related intracerebral hemorrhage, bleeding volume, blood transfusion volume, thromboelastogram the preoperative coagulation function of patients. This study suggests that preoperative platelet transfusion can improve the intraoperative and postoperative bleeding of $\mathrm{ICH}$ patients after antiplatelet therapy to some extent, reducing the blood transfusion volume and the secondary bleeding rate.

\section{Introduction}

Intracerebral hemorrhage ( $\mathrm{ICH})$ is a common cardiovascular and cerebrovascular disease, one of the diseases that cause human death and disability, seriously threatening people's health. The main factors leading to $\mathrm{ICH}$ are hypertensive fine arteriosclerosis, atherosclerotic plaque formation, diabetic microangiopathy, increased blood viscosity, and long-term hypertension (1). Together with the increase of people's living standard and the aging trend, ICH incidence and mortality also increase year by year, ranking only second to tumors, and first in many cities (2). According to the bleeding site, ICH can be divided into several types: lobar hemorrhage, deep hemorrhage, brain stem hemorrhage and cerebellar hemorrhage. Only $20 \%$ of the patients have self-care ability 6 months after onset (3). Antiplatelet drugs can effectively reduce the incidence of ischemic diseases, but excessive inhibition of platelets increases the occurrence of $\mathrm{ICH}$ and the risk of bleeding during treatment (4). Compared with intracranial hemorrhage caused by other reasons, the annual incidence caused by oral antiplatelet drugs has increased by 5.9-12.0 times with mortality $>52 \%$ (5). At present, the antiplatelet drug therapy for $\mathrm{ICH}$ treatment is mainly focused on intraoperative bleeding and postoperative re-bleeding (6).

A retrospective study on antiplatelet drug-related $\mathrm{ICH}$ patients treated in the First Affiliated Hospital of Bengbu Medical College (Bengbu, China) was performed, and the effect of platelet transfusion on the intraoperative bleeding volume, difficulty of hemostasis, and postoperative re-bleeding in antiplatelet drug-related $\mathrm{ICH}$ patients was investigated to provide a theoretical basis for clinical treatment.

\section{Patients and methods}

Patient information. A retrospective study on $82 \mathrm{ICH}$ patients admitted to the First Affiliated Hospital of Bengbu 
Medical College from February 2014 to February 2016 was performed. Among them, 51 patients treated with platelet transfusion served as observation group, including 30 males and 21 females, with an average age of $57 \pm 11.2$ years. Thirty-one patients without platelet transfusion served as control group, including 17 males and 14 females, with an average age of $58 \pm 9.2$ years.

Inclusion and exclusion criteria. Inclusion criteria: patients $>18$ years of age; with definite cardiovascular or cerebrovascular disease; with no history of intracranial hemorrhage; no recent blood donation or blood transfusion; no other organ infection; treated with antiplatelet drugs; with complete clinical data. Exclusion criteria: patients with coagulation disorders; with severe organ dysfunction; not actively involved; with intracranial hemorrhage due to trauma; that had recently used anticoagulant drugs. The study was approved by the Ethics Committee of The First Affiliated Hospital of Bengbu Medical College. All patients had complete clinical data. Signed informed consents were obtained from the patients or their guardians.

Thromboelastography (TEG) detection method. TEG instrument was purchased from Beijing Tailin Dongfang Trading Co., Ltd. (Beijing, China). The detection parameters were: i) clot formation time; ii) reaction time; iii) Angle angle; iv) maximum amplitude (MA); v) EPL value; vi) fibrinolysis indicator (LY30); and vii) arachidonic acid (AA)-induced platelet inhibition rate, and adenosine diphosphate (ADP) also induced it. When AA inhibition rate was $>90 \%$, ADP inhibition rate was $>90 \%$, and maximum blood clot diameter induced by adenosine diphosphate (MAADP) was $<3 \mathrm{~mm}$, the reactivity increased the risk of bleeding with a high drug content. When AA inhibition rate was 50-90\%, ADP inhibition rate was $30-90 \%$, and MAADP ranged from $31-47 \mathrm{~mm}$, the therapeutic effect was satisfactory.

Platelet transfusion. According to the specific condition of the patient's bleeding, 1-3 units of platelets were transfused. A certain amount of apheresis platelets was transfused in strict accordance with the transfusion standard, and TEG was reviewed after $1 \mathrm{~h}$.

Surgical treatment. All patients underwent hematoma removal under general anesthesia, and most of the hematomas were removed under direct microscopy. Bipolar electrocoagulation, hemostatic gauze, and gelatin sponge were used for hemostasis, and the subcutaneous drainage tube was removed 2-3 days after surgery.

Evaluation indicators. Evaluation indicators were intraoperative bleeding volume, blood transfusion volume, postoperative hematoma residual volume, drainage volume and conditions of secondary surgery. The normal value of platelet was $100-300 \times 10^{9} / 1$.

Statistical methods. SPSS 17.0 software (Shanghai Cabit Information Technology Co., Ltd., Shanghai, China) was used for the analysis of all data of this study. Measurement data are presented as mean \pm standard deviation, and count data
Table I. Comparison of clinical characteristics between two groups of patients (n, \%).

\begin{tabular}{|c|c|c|c|c|}
\hline Characteristics & $\begin{array}{l}\text { Observation } \\
\text { group }(\mathrm{n}=51)\end{array}$ & $\begin{array}{c}\text { Control } \\
\text { group }(n=31)\end{array}$ & $\chi^{2} / \mathrm{t}$ & P-value \\
\hline Age (years) & & & 0.017 & 0.982 \\
\hline$\geq 55$ & $32(62.75)$ & $19(61.29)$ & & \\
\hline$<55$ & $19(37.25)$ & $12(38.71)$ & & \\
\hline Sex & & & 0.226 & 0.496 \\
\hline Male & $30(58.82)$ & $17(54.84)$ & & \\
\hline Female & $21(41.18)$ & $14(45.16)$ & & \\
\hline Smoking history & & & 0.059 & 0.821 \\
\hline Yes & $20(39.22)$ & $13(41.94)$ & & \\
\hline No & $31(60.78)$ & $18(58.06)$ & & \\
\hline Diabetes history & & & 1.786 & 0.125 \\
\hline No & $10(19.61)$ & $11(35.48)$ & & \\
\hline Yes & $41(80.39)$ & $20(64.52)$ & & \\
\hline $\begin{array}{l}\text { History of heart } \\
\text { disease }\end{array}$ & & & 0.370 & 0.445 \\
\hline No & $12(23.53)$ & $10(32.26)$ & & \\
\hline Yes & 39 (76.47) & $21(67.74)$ & & \\
\hline Bleeding site & & & 0.606 & 0.315 \\
\hline Basal ganglia & $20(39.22)$ & $10(32.26)$ & & \\
\hline Cerebral ganglion & $10(19.61)$ & $8(25.81)$ & & \\
\hline Cerebellum & $10(19.61)$ & $6(19.35)$ & & \\
\hline Cerebral ventricle & 8 (15.69) & $5(16.13)$ & & \\
\hline Lobe & $3(5.88)$ & $2(6.45)$ & & \\
\hline $\begin{array}{l}\text { Preoperative } \\
\text { bleeding } \\
\text { volume (ml) }\end{array}$ & $64.29 \pm 4.35$ & $63.45 \pm 5.33$ & 0.740 & 0.462 \\
\hline $\begin{array}{l}\text { Diastolic blood } \\
\text { pressure }(\mathrm{mmHg})\end{array}$ & $83.64 \pm 7.92$ & $86.29 \pm 5.67$ & 1.760 & 0.080 \\
\hline $\begin{array}{l}\text { Systolic blood } \\
\text { pressure }(\mathrm{mmHg})\end{array}$ & $145.33 \pm 6.23$ & $146.95 \pm 5.13$ & 1.277 & 0.206 \\
\hline PT (sec) & $11.25 \pm 0.61$ & $10.50 \pm 0.85$ & 1.429 & 0.160 \\
\hline APTT (sec) & $26.32 \pm 2.66$ & $25.41 \pm 1.65$ & 1.912 & 0.060 \\
\hline $\mathrm{Fib}(\mathrm{g} / \mathrm{l})$ & $2.71 \pm 0.52$ & $2.83 \pm 0.42$ & 1.145 & 0.256 \\
\hline
\end{tabular}

PT, prothrombin time; APTT, activated partial thromboplastin time; Fib, fibrinogen.

Table II. Comparison of platelet number between two groups of patients before and after treatment.

\begin{tabular}{|c|c|c|c|c|c|}
\hline \multirow[b]{2}{*}{ Groups } & \multirow[b]{2}{*}{$\mathrm{n}$} & \multicolumn{2}{|c|}{ Platelet number } & \multirow[b]{2}{*}{$\mathrm{t}$} & \multirow[b]{2}{*}{ P-value } \\
\hline & & $\begin{array}{c}\text { Before } \\
\text { treatment } \\
\left(\times 10^{9} / 1\right)\end{array}$ & $\begin{array}{c}\text { After } \\
\text { treatment } \\
\left(\mathrm{x} 10^{9} / 1\right)\end{array}$ & & \\
\hline Observation & 51 & $59.6 \pm 20.1$ & $186.3 \pm 42.3$ & 4.553 & 0.001 \\
\hline Control & 31 & $58.3 \pm 26.5$ & $132.5 \pm 12.6$ & 2.093 & 0.040 \\
\hline $\mathrm{t}$ & & 0.251 & 3.324 & & \\
\hline P-value & & 0.802 & 0.001 & & \\
\hline
\end{tabular}


Table III. Comparison of treatment status between two groups of patients.

\begin{tabular}{lcccc}
\hline Groups & $\begin{array}{c}\text { Intraoperative } \\
\text { bleeding volume }(\mathrm{ml})\end{array}$ & $\begin{array}{c}\text { Blood transfusion } \\
\text { volume }(\mathrm{ml})\end{array}$ & $\begin{array}{c}\text { Postoperative hematoma } \\
\text { residual volume (ml) }\end{array}$ & $\begin{array}{c}\text { Drainage volume (ml) } \\
\text { Observation }(\mathrm{n}=51)\end{array}$ \\
Control (n=31) & $506.00 \pm 111.32$ & $200.00(0-600.00)$ & $12.35 \pm 2.62$ & $105.68 \pm 20.62$ \\
t/Z & 1.994 & $652.00(0-1,200.00)$ & $23.53 \pm 5.12$ & $211.44 \pm 45.31$ \\
P-value & 0.050 & 2.681 & 2.145 & 2.401 \\
& & 0.036 & 0.035 & 0.019 \\
\hline
\end{tabular}

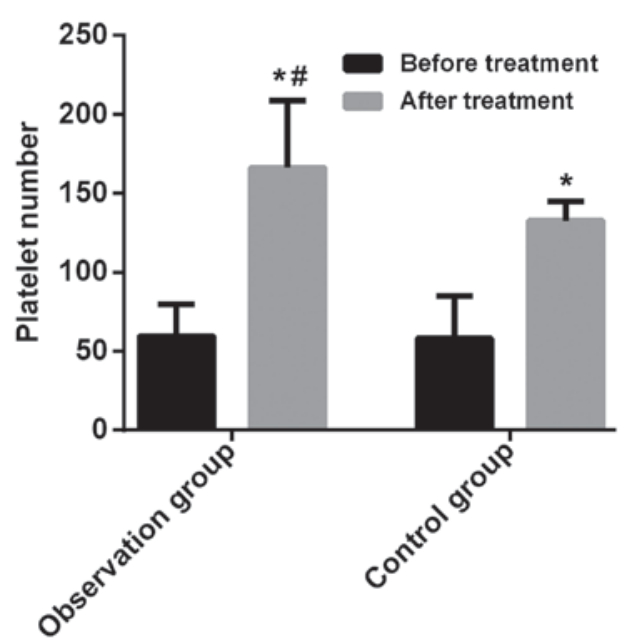

Figure 1. Comparison of platelet number between two groups of patients before and after treatment. The difference in the platelet number of the two groups before treatment was not statistically significant $(\mathrm{P}>0.05)$. The platelet number after treatment was significantly increased in both groups $\left({ }^{*} \mathrm{P}<0.05\right)$, and it was higher in observation group than in control group, with a statistically significant difference $\left({ }^{\#} \mathrm{P}<0.05\right)$.

as rate (\%). Paired t-test was used for the comparison of data before and after treatment (Table II). ANOVA was used for comparisons between groups, and Dunnett's test was used as a post hoc test. $\chi^{2}$ test was used for count data. Intraoperative total blood transfusion volume, as a kind of skewed distribution measurement data, was measured using rank sum test and expressed as median (interquartile range) $[\mathrm{M}(\mathrm{Q})]$. $\mathrm{P}<0.05$ was considered to indicate a statistically significant difference.

\section{Results}

Basic information. The difference was not statistically significant in sex, age, smoking history, diabetes history, history of heart disease, bleeding site, preoperative bleeding volume, diastolic blood pressure, systolic blood pressure, prothrombin time (PT), activated partial thromboplastin time (APTT), and fibrinogen (Fib) between the two groups (P>0.05) (Table I).

Platelet number of two groups of patients before and after treatment. The difference in the platelet number before treatment was not statistically significant between the two groups $(\mathrm{P}>0.05)$. After treatment, the platelet number in the two groups of patients significantly increased, and the platelet number in the observation group was higher than that

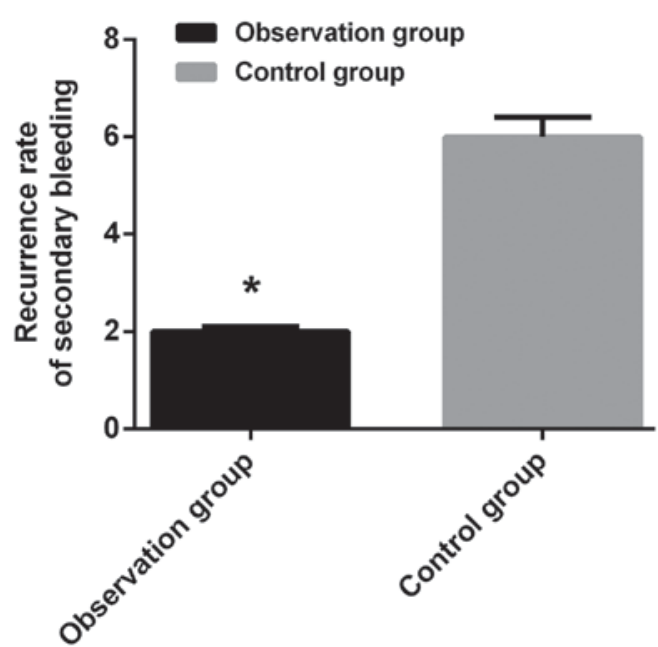

Figure 2. Comparison of recurrence rate after postoperative bleeding between two groups of patients. The recurrence rate of secondary bleeding in observation group was significantly lower than that in control group, with a statistically significant difference $\left({ }^{*} \mathrm{P}<0.05\right)$.

in control group, with a statistically significant difference $(\mathrm{P}<0.05)$ (Table II; Fig. 1).

Treatment effect. The intraoperative bleeding volume, blood transfusion volume, postoperative hematoma residual volume and drainage volume in observation group were lower than those in control group, and the differences were statistically significant $(\mathrm{P}<0.05)$. There were 54 cases with MAADP $<20 \mathrm{~mm}$ and 28 cases with MAADP $>20 \mathrm{~mm}$ (Table III).

Postoperative bleeding in two groups of patients. Only $3.92 \%$ of the patients in observation group and $19.35 \%$ in control group had secondary surgery due to postoperative re-bleeding, and the comparison of the rate of secondary bleeding between the two groups was statistically significant $\left(\chi^{2}=3.610\right.$, $\mathrm{P}=0.048)(\mathrm{P}<0.05)($ Fig. 2).

\section{Discussion}

$\mathrm{ICH}$ is a severe cardiovascular and cerebrovascular disease. In Europe and the United States, 50,000-110,000 patients experience ICH every year, and its incidence is on the rise due to the increase in aging population (7). In China, the incidence of $\mathrm{ICH}$ ranks second only to that of ischemic cerebral death, and mortality rate at 30 days after $\mathrm{ICH}$ is $21-39 \%$, with approximately half of the patients dying within $48 \mathrm{~h}$ from the onset of the disease (8). Antiplatelet drugs have 
been widely used in primary and secondary prevention of cardiovascular and cerebrovascular diseases to reduce the incidence of thromboembolic events (6). In recent years, antiplatelet therapeutic drugs have been increasingly used in the clinic. Correspondingly, the incidence of concurrent $\mathrm{ICH}$ has also increased year by year. Once a significant increase in intracranial pressure is caused, an urgent surgical intervention is needed (9). Coagulation dysfunction is a taboo for surgery, so the treatment of such patients is more difficult.

The results of this study revealed that the platelet number after treatment significantly increased in both groups, and in observation group it was significantly higher than that in control group $(\mathrm{P}<0.05)$. Platelet transfusion could improve the coagulation function of patients and reduce the amount of ICH (10). In the early stages of the disease, exogenously supplemented platelets can participate in the process of thrombosis and coagulation, thereby forming thrombus as soon as possible through the ruptured blood vessel wall, rapidly stopping bleeding, and increasing platelet count (11). TEG can quickly and accurately respond to platelet function, and can detect coagulation abnormalities that cannot be detected by traditional coagulation (12). Patients' platelet function was evaluated before surgery, and patients with oral antiplatelet drugs had excessive inhibition of platelet function. Platelet transfusion was used in patients with platelet inhibition rates $>87 \%$ prior to enrollment. The intraoperative bleeding volume, blood transfusion volume, postoperative hematoma residual volume and drainage volume were compared between the two groups of patients, and observation group was superior to control group, with a statistically significant difference $(\mathrm{P}<0.05)$. After treatment with platelet transfusion, the difficulty of intraoperative hemostasis was reduced, and the intraoperative bleeding volume, blood transfusion volume and probability of postoperative re-bleeding were reduced, indicating that targeted platelet transfusion before surgery could improve the intraoperative bleeding in ICH patients and reduce the occurrence of major bleeding (13). TEG detection can accurately assess the patient's platelet function and provides the possibility of individualized platelet transfusion (14). This study showed that the incidence of secondary surgery in control group was significantly higher than that in observation group, and the difference between the two groups was statistically significant $(\mathrm{P}<0.05)$. The concentration of antiplatelet drugs decreases in $\mathrm{ICH}$ patients treated with platelet transfusion, and it cannot inhibit the new platelet transfusion function, so the efficacy is optimal (15). TEG detection can reduce the waste of platelet transfusion as much as possible, and can promptly correct the abnormal platelet function of $\mathrm{ICH}$ patients during and after surgery. It also assists with improving the safety and timeliness of postoperative antiplatelet therapy (16).

This study attempted to overcome the bias and disadvantages caused by the uncertainty in the detection of platelet function of previous studies. Since the patients in this study were all surgical patients, whether the TEG detection method under the guidance of platelet transfusion therapy can reduce the risk of conservative treatment of re-bleeding in $\mathrm{ICH}$ patients needs to be further studied.

In conclusion, TEG detection indicators can more accurately evaluate the preoperative coagulation function of patients. Targeted platelet transfusion before surgery can improve the intraoperative and postoperative bleeding and reduce blood transfusion volume in $\mathrm{ICH}$ patients.

\section{Acknowledgements}

Not applicable.

\section{Funding}

No funding was received.

\section{Availability of data and materials}

The datasets used and/or analyzed during the present study are available from the corresponding author on reasonable request.

\section{Authors' contributions}

$\mathrm{HZ}$ was responsible for the thrombelastographic detection method. LC and HH contributed to platelet transfusion and surgical treatment. All authors read and approved the final manuscript.

\section{Ethics approval and consent to participate}

The study was approved by the Ethics Committee of The First Affiliated Hospital of Bengbu Medical College (Bengbu, China). Patients who participated in this research had complete clinical data. Signed informed consents were obtained from the patients or their guardians.

\section{Patient consent for publication}

Not applicable.

\section{Competing interests}

The authors declare that they have no competing interests.

\section{References}

1. An SJ, Kim TJ and Yoon BW: Epidemiology, risk factors, and clinical features of intracerebral hemorrhage: An update. J Stroke 19: 3-10, 2017.

2. Inagawa T, Ohbayashi N, Takechi A, Shibukawa M and Yahara K: Primary intracerebral hemorrhage in Izumo City, Japan: incidence rates and outcome in relation to the site of hemorrhage. Neurosurgery 53: 1283-1297; discussion 1297-1288, 2003.

3. Rosand J, Eskey C, Chang Y, Gonzalez RG, Greenberg SM and Koroshetz WJ: Dynamic single-section CT demonstrates reduced cerebral blood flow in acute intracerebral hemorrhage. Cerebrovasc Dis 14: 214-220, 2002.

4. Katsanos K, Spiliopoulos S, Saha P, Diamantopoulos A, Karunanithy N, Krokidis M, Modarai B and Karnabatidis D: Comparative efficacy and safety of different antiplatelet agents for prevention of major cardiovascular events and leg amputations in patients with peripheral arterial disease: A systematic review and network meta-analysis. PLoS One 10: e0135692, 2015.

5. Sugiyama N, Matsuda S, Shimizu M, Obara S, Ikegami M, Yokoyama J, Miyashita Y, Takizawa S and Takagi S: Recurrent idiopathic cerebral infarction in a 5-year-old boy, with emphasis on the importance of platelet aggregation analysis for appropriate selection of anti-platelet drugs. No To Hattatsu 41: 47-51, 2009 (In Japanese). 
6. Gouya G, Arrich J, Wolzt M, Huber K, Verheugt FW, Gurbel PA, Pirker-Kees A and Siller-Matula JM: Antiplatelet treatment for prevention of cerebrovascular events in patients with vascular diseases: A systematic review and meta-analysis. Stroke 45: 492-503, 2014.

7. Xing Y, An Z, Zhang X, Yu N, Zhao W, Ning X and Wang J: Sex differences in the clinical features, risk factors, and outcomes of intracerebral hemorrhage: A large hospital-based stroke registry in China. Sci Rep 7: 286, 2017.

8. Han JH, Lee JM, Koh EJ and Choi HY: The spot sign predicts hematoma expansion, outcome, and mortality in patients with primary intracerebral hemorrhage. J Korean Neurosurg Soc 56 303-309, 2014

9. Shih FY, Chang HH, Wang HC, Lee TH, Lin YJ, Lin WC, Chen WF, $\mathrm{Ho}$ JT and Lu CH: Risk factors for delayed neuro-surgical intervention in patients with acute mild traumatic brain injury and intracranial hemorrhage. World J Emerg Surg 11: 13, 2016.

10. Baschin M, Selleng S, Zeden JP, Westphal A, Kohlmann T, Schroeder HW, Greinacher A and Thiele T: Platelet transfusion to reverse antiplatelet therapy before decompressive surgery in patients with intracranial haemorrhage. Vox Sang 112: 535-541, 2017.

11. Yue M, Luo D, Yu S, Liu P, Zhou Q, Hu M, Liu Y, Wang S, Huang Q, Niu Y, et al: Misshapen/NIK-related kinase (MINK1) is involved in platelet function, hemostasis, and thrombus formation. Blood 127: 927-937, 2016.

12. Lisman T and Porte RJ: The role of platelets in liver inflammation and regeneration. Semin Thromb Hemost 36: 170-174, 2010.
13. Estcourt LJ, Stanworth SJ, Doree C, Hopewell S, Trivella M and Murphy MF: Comparison of different platelet count thresholds to guide administration of prophylactic platelet transfusion for preventing bleeding in people with haematological disorders after myelosuppressive chemotherapy or stem cell transplantation. Cochrane Database Syst Rev (11): CD010983, 2015.

14. Mishra PK, Thekkudan J, Sahajanandan R, Gravenor M, Lakshmanan S, Fayaz KM and Luckraz H: The role of point-of-care assessment of platelet function in predicting postoperative bleeding and transfusion requirements after coronary artery bypass grafting. Ann Card Anaesth 18: 45-51, 2015.

15. Spiess BD, Royston D, Levy JH, Fitch J, Dietrich W, Body S, Murkin J and Nadel A: Platelet transfusions during coronary artery bypass graft surgery are associated with serious adverse outcomes. Transfusion 44: 1143-1148, 2004.

16. Joseph B, Pandit V, Sadoun M, Larkins CG, Kulvatunyou N, Tang A, Mino M, Friese RS and Rhee P: A prospective evaluation of platelet function in patients on antiplatelet therapy with traumatic intracranial hemorrhage. J Trauma Acute Care Surg 75: 990-994, 2013.

This work is licensed under a Creative Commons Attribution-NonCommercial-NoDerivatives 4.0 International (CC BY-NC-ND 4.0) License. 